\title{
KESIAPAN MANAJEMEN PUSKESMAS DALAM MENJALANKAN PROGRAM INDONESIA SEHAT DENGAN PENDEKATAN KELUARGA (PIS-PK) DI INDONESIA
}

\section{(The Readiness of Primary Health Care's Management to Run Indonesian Health Program with Family Approach, Indonesia)}

\author{
Mujiati $^{1}$, Sugiharti ${ }^{2}$, Siti Masitoh ${ }^{2}$, Eva Laelasari $^{2}$ \\ ${ }^{1}$ Pusat Penelitian dan Pengembangan Sumber Daya dan Pelayanan Kesehatan \\ ${ }^{2}$ Pusat Penelitian dan Pengembangan Upaya Kesehatan Masyarakat \\ Email: mujiati.kemenkes@gmail.com
}

Diterima: 6 Maret 2020; Direvisi: 20 Juli 2020; Disetujui: 23 September 2020

\begin{abstract}
Indonesian Health Program with Family Approach (PIS-PK) is one of the health development priority programs by visiting family to increase target coverage and access to health services. This research was conducted by quantitative approach through interview using a structured questionnaire to Head of PHC or Head of Administration Division or PIS-PK officer) or PHC officer who understand about PIS-PK in 9699 PHC in 34 provinces. Data were analyzed descriptively. The results showed that PHC that had been trained in PIS-PK was better prepared in management compared to PHC that had not been trained. PHC that had been trained by PIS-PK were better prepared in availability of human resources, budget, RUK and RPK, availability of PIS-PK instruments, presence of socialization, availability of computers with internet access, monthly and quarterly administration has been carried out, and presence evaluation. PHC are expected to prepare these aspects so that they can be prepared management to carry out PIS-PK. It is expected that District/ city health offices able to carry out routine monitoring and evaluation, supervision and technical assistance to the PHC.
\end{abstract}

Keywords: Readiness; Primary health care's management; Indonesian Health Program with Family Approach

\begin{abstract}
ABSTRAK
Program Indonesia Sehat dengan Pendekatan Keluarga (PIS-PK) merupakan salah satu program prioritas pembangunan kesehatan yang dilaksanakan oleh Puskesmas dengan cara mendatangi keluarga untuk meningkatkan jangkauan sasaran dan akses pelayanan kesehatan. Program PIS-PK dilaksanakan secara bertahap sejak tahun 2016, oleh karena itu perlu dilakukan analisis tentang kesiapan manajemen Puskesmas dalam menjalankan PIS-PK. Analisis dilakukan dengan menggunakan data laporan Riset Ketenagaan Kesehatan (Risnakes) 2017 terpublikasi. Data Risnakes dikumpulkan dengan pendekatan kuantitatif melalui wawancara menggunakan kuesioner terstruktur pada Kepala Puskesmas, Kepala Bagian Tata Usaha atau Penanggungjawab PIS-PK atau petugas puskesmas yang memahami tentang PIS-PK di 9.697 Puskesmas di 34 provinsi. Hasil analisis menunjukkan Puskesmas yang sudah melaksanakan pelatihan PISPK (78,8\%) lebih siap secara manajemen dibanding dengan Puskesmas yang belum melaksanakan pelatihan PIS-PK (49,9\%). Kesiapan dalam pelaksanaan PIS-PK karena puskesmas lebih siap dalam aspek ketersediaan SDM, anggaran, telah disusunnya RUK dan RPK, ketersediaan instrumen PIS-PK, adanya sosialisasi, ketersediaan komputer dengan akses internet, telah dilakukannya lokmin bulanan dan triwulanan, serta adanya evaluasi kehadiran. Puskesmas diharapkan dapat menyiapkan aspek-aspek tersebut agar siap secara manajemen untuk menjalankan PIS-PK. Diharapkan Dinas Kesehatan Kabupaten/Kota dapat melakukan monitoring, evaluasi, supervisi dan bimbingan teknis program secara rutin kepada puskesmas.
\end{abstract}

Kata kunci: Manajemen puskesmas, pelatihan, PIS-PK 


\section{PENDAHULUAN}

Pembangunan

kesehatan

diselenggarakan untuk meningkatkan kesadaran, kemauan, dan kemampuan hidup sehat bagi setiap orang agar terwujud derajat kesehatan masyarakat yang setinggitingginya. Dalam dokumen Renstra Kementerian Kesehatan 2015-2019, Program Indonesia dilakukan melalui 3 pilar prioritas, yaitu paradigma sehat, penguatan pelayanan kesehatan dan jaminan kesehatan nasional. Ketiga pilar tersebut dilaksanakan secara terintegrasi dengan sasaran difokuskan pada keluarga sebagai unit masyarakat terkecil., Program tersebut kemudian lebih dikenal dengan Program Indonesia Sehat dengan Pendekatan Keluarga (PIS-PK) yang dilakukan oleh Puskesmas di wilayah kerjanya.

PIS-PK adalah salah satu cara Puskesmas untuk meningkatkan jangkauan sasaran, mendekatkan dan meningkatkan akses pelayanan kesehatan di wilayah kerjanya dengan mendatangi keluarga (Kementerian Kesehatan, 2016) Tujuan penyelenggaraan PIS-PK adalah meningkatkan akses keluarga terhadap pelayanan kesehatan yang komprehensif, mendukung pencapaian Standar Pelayanan Minimal (SPM) kabupaten/kota, mendukung pelaksanaan Jaminan Kesehatan Nasional (JKN), dan mendukung tercapainya Program Indonesia Sehat sesuai dalam rencana strategis Kementerian Kesehatan tahun 20152019. Puskesmas tidak hanya menyelenggarakan pelayanan kesehatan di dalam gedung saja, melainkan juga ke luar gedung dengan mengunjungi keluarga dalam wilayah kerja puskesmas (Kementerian Kesehatan RI, 2016). Dengan cara kerja tersebut, puskesmas tidak hanya mengandalkan Upaya Kesehatan Berbasis Masyarakat (UKBM), tetapi berkunjung langsung ke keluarga-keluarga yang ada dalam wilayah kerja puskesmas, sehingga Puskesmas dapat mengidentifikasi masalahmasalah kesehatan yang dihadapi keluarga secara menyeluruh (holistik). PIS-PK dilaksanakan secara bertahap, mulai tahun 2016 dilaksanakan pada 9 provinsi di 64 kabupaten/kota, pada 470 puskesmas prioritas yang jumlah kematian ibu dan bayi lahir masih tinggi. Selanjutnya, PIS-PK dilaksanakan pada 34 provinsi di 514 kabupaten/kota secara bertahap. Tahun 2017 dilaksanakan pada 2.926 Puskesmas, pada tahun 2018 dilaksanakan pada 5.852 puskesmas dan pada tahun 2019 seluruh puskesmas diharapkan sudah melaksanakan PIS-PK (Pusat Data dan Informasi Kementerian Kesehatan, 2018).

Data dari Pusat Data dan Informasi (Pusdatin) Kemenkes RI menunjukkan sampai dengan tanggal 10 Februari 2018, jumlah keluarga yang telah melaksanakan aplikasi Keluarga Sehat sebanyak 6.438.003 keluarga yang tersebar di 34 provinsi dengan jumlah kunjungan tertinggi di Jawa Timur sebanyak 1.211.837 keluarga dan Jawa Tengah sebanyak 1.097.891 keluarga. (Pusdatin Kemenkes RI, 2018)

(SKN) $\begin{array}{rr}\text { Dalam Sistem Kesehatan Nasional } \\ \text { disebutkan }\end{array}$ menggerakkan pembangunan kesehatan yang berhasil guna dan berdaya guna, diperlukan manajemen kesehatan. Peran manajemen kesehatan adalah koordinasi, integrasi, regulasi, sinkronisasi, dan harmonisasi berbagai subsistem SKN agar efektif, efisien, dan transparan dalam penyelenggaraan SKN tersebut (Republik Indonesia, 2012). Manajemen program/pelayanan kesehatan Puskesmas dilaksanakan melalui tiga tahapan, yaitu: Perencanaan (P1) adalah tahap menyusun rencana usulan kegiatan (RUK) dan rencana pelaksanaan kegiatan (RPK) yang didasari oleh fakta dan data; Penggerakan-Pelaksanaan (P2) adalah tahap melaksanakan hal-hal yang sudah tercantum dalam RPK. Untuk mendorong pencapaian program pelayanan kesehatan dilakukan melalui lokakarya mini (lokmin) secara berkala; serta Pengawasan-PengendalianPenilaian (P3). Lokmin dan P3 adalah tahap memantau perkembangan pencapaian, Penilaian pencapaian dan koreksi pelaksanaan kegiatan, dilakukan pada pertengahan dan akhir tahun (Kementerian Kesehatan, 2016c).

Pelaksanaan pendekatan keluarga di Puskesmas dilakukan melalui beberapa tahapan yaitu pendataan menggunakan formulir prokesga, pembuatan dan pengelolaan pangkalan data, analisis data, perumusan intervensi masalah kesehatan dan penyusunan rencana Puskesmas, penyuluhan 
kesehatan, pengorganisasian masyarkat dan pembinaan UKBM dan pelaksanaan pelayanan kesehatan baik di dalam dan di luar gedung (Petunjuk Teknis Penguatan Manajemen Puskesmas dengan Pendekatan Keluarga). Kegiatan-kegiatan tersebut harus diintegrasikan ke dalam langkah-langkah manajemen Puskesmas yang mencakup P1 (Perencanaan), P2 (PenggerakanPelaksanaan), dan P3 (PengawasanPengendalian-Penilaian) (Kementerian Kesehatan RI, 2014). Manajemen puskesmas yang dilakukan secara terpadu dan berkesinambungan diharapkan dapat menghasilkan kinerja Puskesmas yang efektif dan efisien (Kementerian Kesehatan, 2016b).

Permenkes Nomor 43 tahun 2019 tentang Puskesmas menunjukkan bahwa untuk mencapai tujuan pembangunan kesehatan di wilayah kerjanya, Puskesmas mengintegrasikan program yang dilaksanakannya dengan pendekatan keluarga. Penilaian kesiapan manajemen Puskesmas penting dilakukan karena manajemen Puskesmas merupakan salah satu kunci untuk menentukan keberhasilan program-program Puskesmas. Saat ini program PIS-PK masih dan sedang berjalan, sehingga pembahasan tentang kesiapan manajemen puskesmas masih relevan karena informasi ini menjadi salah satu kunci keberhasilan program kesehatan yang dilakukan oleh puskesmas, termasuk PIS-PK. Program PIS-PK yang sudah dimulai sejak tahun 2016 perlu dievaluasi, khususnya dari sisi manajemen Puskesmas agar bisa diketahui faktor pendukung keberhasilan program dan dapat dimanfaatkan sebagai bahan perbaikan program.

Tujuan penulisan artikel ini adalah menyusun informasi tentang kesiapan manajemen Puskesmas dalam menjalankan PIS-PK. .

\section{BAHAN DAN CARA}

Artikel ini disusun berdasarkan sumber data hasil Riset Ketenagaan Kesehatan (Risnakes) tahun 2017 milik Badan Litbangkes yang telah mendapatkan persetujuan etik dari Komisi etik Badan
Litbangkes (No. LB. 02.01/ 2/KE/ 130/ 2017 tanggal 5 April 2017).

Penelitian ini adalah tentang kesiapan manajemen Puskesmas dalam menjalankan PIS-PK, merupakan bagian dari Riset Ketenagaan Kesehatan Tahun 2017 yang dilakukan di seluruh Puskesmas di Indonesia. sebanyak 9.699 Puskesmas.Desain penelitian adalah potong lintang (cross sectional), pengumpulan data dilakukan melalui wawancara terstruktur menggunakan kuesioner kepada Kepala Puskesmas atau Kepala Bagian Tata Usaha atau Penanggungjawab PIS-PK atau petugas Puskesmas yang mengerti tentang PIS-PK . Sebanyak 9.697 dari 9.699 puskesmas di Indonesia telah dikunjungi untuk dilakukan pengumpulan data. Dua (2) puskesmas tidak bisa diambil data, karena sama sekali tidak mempunyai data data pelaksanaan PISPK. Data yang dikumpulkan berupa data kuantitatif dan data dianalisis secara deskriptif per provinsi. Analisis tingkat provinsi ini bertujuan untuk mendapatkan gambaran kesiapan manajamen puskesmas secara umum di tingkat provinsi, sehingga diketahui provinsi mana yang siap dan belum siap secara manajemen dalam melaksanakan PIS-PK. Selain itu, gambaran di tingkat provinsi ini dapat menjadi informasi awal untuk melakukan analisis lebih lanjut di tingkat kabupaten/kota maupun di tingkat puskesmas.Analisis data dilakukan dengan membagi 2 kelompok berdasarkan keikut sertaan puskesmas dalam pelatihan PIS-PK., Kelompok tersebut adalah 3.696 Puskesmas yang sudah mendapat pelatihan PIS-PK dan 6.001 Puskesmas yang belum mendapat pelatihan PIS-PK, dan selanjutnya masingmasing Puskesmas dilakukan analisa tentang kesiapan manajemennya.

Penentuan kesiapan puskesmas dinilai melalui 3 jenis kesiapan yaitu kesiapan P1, P2 dan P3. Kesiapan P1 adalah kesiapan pada tahap perencanaan puskesmas untuk menjalankan PIS-PK, kesiapan P2 adalah kesiapan puskesmas dalam tahap penggerakan dan pelaksanaan dan kesiapan P3 adalah kesiapan puskesmas dalam tahap pengawasan. Tahapan dalam melakukan analisis data dapat dilihat pada tabel berikut: 
Tabel 1. Langkah analisis data kesiapan manajemen puskesmas dalam menjalankan PIS-PK

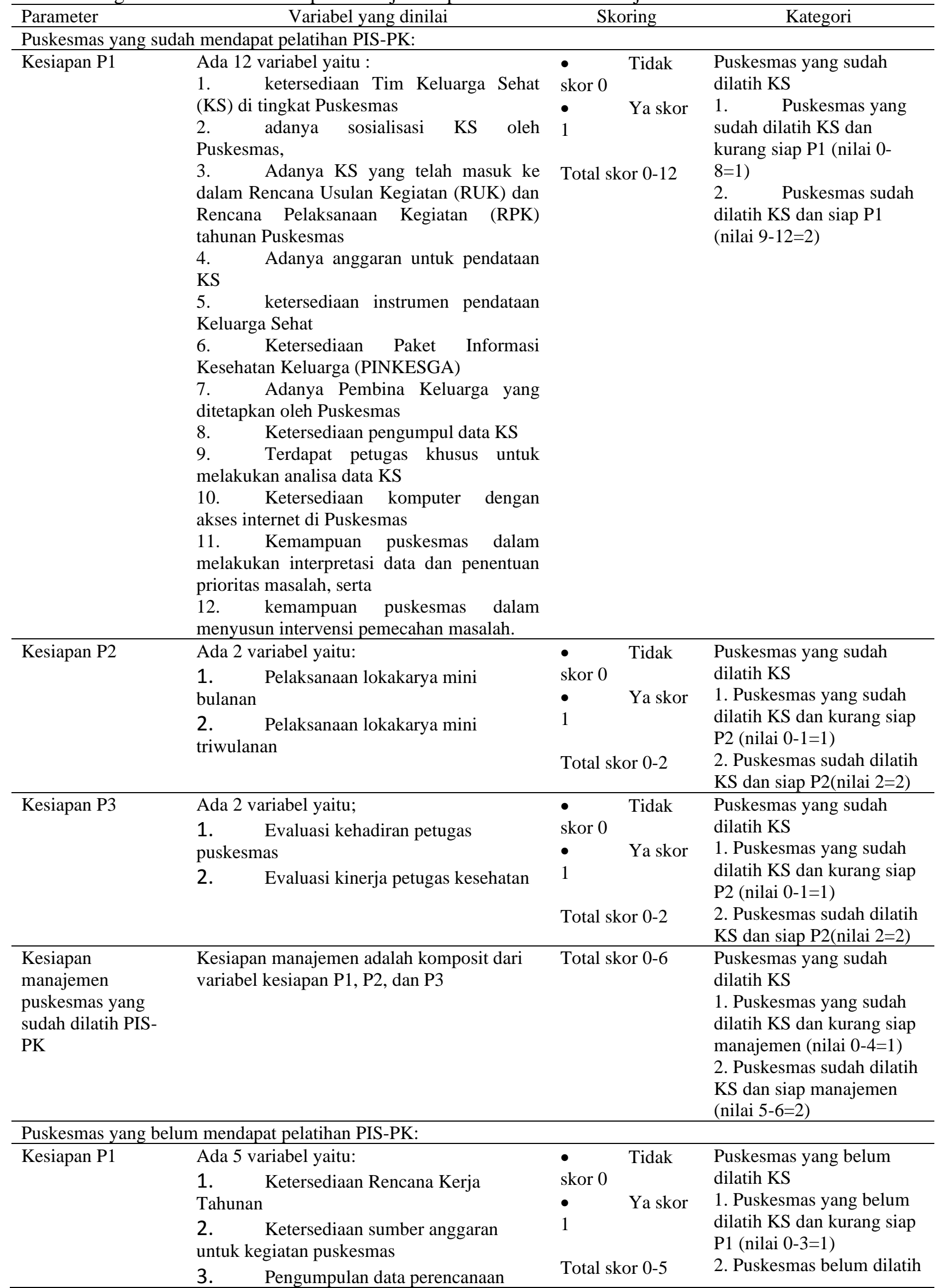




\begin{tabular}{|c|c|c|c|}
\hline & \multicolumn{2}{|l|}{ oleh petugas puskesmas } & \multirow{3}{*}{$\begin{array}{l}\text { KS dan siap P1(nilai 4- } \\
5=2)\end{array}$} \\
\hline & $\begin{array}{l}\text { 4. Ketersediaan petugas khusus untuk } \\
\text { analisis data }\end{array}$ & & \\
\hline & $\begin{array}{l}5 . \quad \text { Keterlibatan penanggungjawab } \\
\text { program dalam proses perencanaan } \\
\text { puskesmas. }\end{array}$ & & \\
\hline \multirow[t]{4}{*}{ Kesiapan P2 } & Ada 3 variabel yaitu & & \multirow{4}{*}{$\begin{array}{l}\text { Puskesmas yang belum } \\
\text { dilatih KS } \\
\text { 1. Puskesmas yang belum } \\
\text { dilatih KS dan kurang siap } \\
\text { P2 (nilai } 0-2=1 \text { ) } \\
\text { 2. Puskesmas belum dilatih } \\
\text { KS dan siap P2(nilai } 3=2 \text { ) }\end{array}$} \\
\hline & $\begin{array}{l}\text { 1. Dilaksanakannya apel pagi oleh } \\
\text { puskesmas }\end{array}$ & skor 0 & \\
\hline & $\begin{array}{l}2 . \quad \text { Dilaksanakannya lokakarya mini } \\
\text { bulanan }\end{array}$ & 1 & \\
\hline & $\begin{array}{l}\text { 3. Dilaksanakannya lokakarya mini } \\
\text { triwulanan. }\end{array}$ & Total skor 0-3 & \\
\hline \multirow[t]{4}{*}{ Kesiapan P3 } & Ada 3 variabel yaitu: & \multirow{4}{*}{\begin{tabular}{ll} 
& Tidak \\
skor 0 & \\
$\bullet$ & Ya skor \\
1 & \\
\multicolumn{2}{l}{ Total skor $0-3$}
\end{tabular}} & \multirow{4}{*}{$\begin{array}{l}\text { Puskesmas yang belum } \\
\text { dilatih KS } \\
\text { 1. Puskesmas yang belum } \\
\text { dilatih KS dan kurang siap } \\
\text { P3 (nilai } 0-2=1 \text { ) } \\
\text { 2. Puskesmas belum dilatih } \\
\text { KS dan siap P3 (nilai 3=2) }\end{array}$} \\
\hline & $\begin{array}{l}1 . \quad \text { Adanya kunjungan petugas dinas } \\
\text { kesehatan untuk melakukan supervisi atau } \\
\text { bimbingan teknis program }\end{array}$ & & \\
\hline & \multirow{2}{*}{$\begin{array}{l}\text { 2. Adanya pertemuan monitoring dan } \\
\text { evaluasi program di Dinas Kesehatan } \\
\text { 3. Adanya penilaian kinerja. }\end{array}$} & & \\
\hline & & & \\
\hline $\begin{array}{l}\text { Kesiapan } \\
\text { manajemen } \\
\text { puskesmas yang } \\
\text { belum dilatih PIS- } \\
\text { PK }\end{array}$ & $\begin{array}{l}\text { Komposit dari variabel Kesiapan P1, P2 dan } \\
\text { P3 }\end{array}$ & Total 0-6 & $\begin{array}{l}\text { Puskesmas yang belum } \\
\text { dilatih KS } \\
\text { 1. Puskesmas yang belum } \\
\text { dilatih KS dan kurang siap } \\
\text { manajemen (nilai } 0-4=1 \text { ) } \\
\text { 2. Puskesmas belum dilatih } \\
\text { KS dan siap manajemen } \\
\text { (nilai 5-6=2) }\end{array}$ \\
\hline
\end{tabular}

Dalam menentukan kesiapan puskesmas akan dibedakan antara puskesmas yang sudah pelatihan PIS-PK dan yang belum mendapat pelatihan PIS-PK karena variabel yang dilihat pun akan berbeda. Penilaian dilakukan secara bertahap mulai dari menilai kesiapan P1, P2, dan P3 secara terpisah dengan skor 1 jika 'kurang siap' dan 2 jika 'siap', baru kemudian dinilai kesiapan manajemen secara keseluruhan dari hasil komposit kesiapan P1, P2 dan P3. Puskesmas dikategorikan siap secara manajemen jika memiliki skor komposit 5-6. Pada Puskesmas yang sudah mendapat pelatihan KS, untuk menilai kesiapan P1 ada 12 variabel yang dinilai, kesiapan P2 ada 2 variabel dan kesiapan P3 ada 3 variabel, dimana masingmasing variabel diberikan skor 1 jika ya dan 0 jika tidak. Puskesmas dikagetorikan siap P1 jika memiliki skor 9-12, siap P2 jika skor 2 dan siap P3 jika skor 2. Sedangkan pada Puskesmas yang belum mendapat pelatihan KS kesiapan P1 ada 5 variabel yang dinilai, kesiapan P2 ada 3 variabel dan kesiapan P3 ada 3 variabel. Puskesmas dikagetorikan siap
P1 jika memiliki skor 4-5, siap P2 jika skor 3 dan siap P3 jika skor 3.

Analisis ini mempunyai kelemahan oleh karena yang dinilai adalah aspek-aspek manajemen seperti RUK, RPK, anggaran pendataan KS, ketersediaan instrument pendataan Keluarga Sehat, ketersediaan PINKESGA, Pembina Keluarga, ketersediaan pengumpul data, apel pagi, monitoring dan evaluasi, dan lain-lain yang bisa tergantung dari norma atau kewenangan tingkat kabupaten/kota, sehingga kesiapan puskesmas dalam satu kabupaten/kota bisa saja sama. Idealnya analisis dilakukan menurut kabupaten/kota, namun dalam artikel ini analisis dilakukan di tingkat provinsi.

\section{HASIL}

Jumlah Puskesmas berdasarkan keikutsertaan dalam pelatihan PIS-PK per provinsi ditunjukkan secara rinci pada Tabel 2. 
Tabel 2. Persentase keikutsertaan puskesmas dalam pelatihan PIS-PK berdasarkan provinsi

\begin{tabular}{|c|c|c|c|c|c|c|}
\hline \multirow[t]{2}{*}{ No. } & \multirow[t]{2}{*}{ Nama Provinsi } & \multirow{2}{*}{$\begin{array}{c}\text { Jumlah } \\
\text { Puskesmas }\end{array}$} & \multicolumn{2}{|c|}{$\begin{array}{l}\text { Puskesmas sudah } \\
\text { dilatih PIS-PK }\end{array}$} & \multicolumn{2}{|c|}{$\begin{array}{l}\text { Puskesmas belum } \\
\text { dilatih PIS-PK }\end{array}$} \\
\hline & & & & $\%$ & $\mathrm{~N}$ & \\
\hline 1 & Aceh & 340 & 195 & 57,4 & 145 & 42,6 \\
\hline 2 & Sumatra Utara & 571 & 292 & 51,1 & 279 & 48,9 \\
\hline 3 & Sumatra Barat & 264 & 109 & 41,3 & 155 & 58,7 \\
\hline 4 & Riau & 212 & 88 & 41,5 & 124 & 58,5 \\
\hline 5 & Jambi & 176 & 79 & 44,9 & 97 & 55,1 \\
\hline 6 & Sumatra Selatan & 322 & 128 & 39,8 & 194 & 60,2 \\
\hline 7 & Bengkulu & 179 & 51 & 28,5 & 128 & 71,5 \\
\hline 8 & Lampung & 291 & 210 & 72,2 & 81 & 27,8 \\
\hline 9 & Kepulauan Bangka Belitung & 62 & 26 & 41,9 & 36 & 58,1 \\
\hline 10 & Kepulauan Riau & 72 & 48 & 66,7 & 24 & 33,3 \\
\hline 11 & DKI Jakarta & 314 & 93 & 29,6 & 221 & 70,4 \\
\hline 12 & Jawa Barat & 1050 & 352 & 33,5 & 698 & 66,5 \\
\hline 13 & Jawa Tengah & 875 & 474 & 54,2 & 401 & 45,8 \\
\hline 14 & DI Yogyakarta & 121 & 35 & 28,9 & 86 & 71,1 \\
\hline 15 & Jawa Timur & 960 & 481 & 50,1 & 479 & 49,9 \\
\hline 16 & Banten & 233 & 97 & 41,6 & 136 & 58,4 \\
\hline 17 & Bali & 120 & 50 & 41,7 & 70 & 58,3 \\
\hline 18 & Nusa Tenggara Barat & 158 & 95 & 60,1 & 63 & 39,9 \\
\hline 19 & Nusa Tenggara Timur & 371 & 42 & 11,3 & 329 & 88,7 \\
\hline 20 & Kalimantan Barat & 238 & 61 & 25,6 & 177 & 74,4 \\
\hline 21 & Kalimantan Tengah & 195 & 29 & 14,9 & 166 & 85,1 \\
\hline 22 & Kalimantan Selatan & 230 & 81 & 35,2 & 149 & 64,8 \\
\hline 23 & Kalimantan Timur & 173 & 53 & 30,6 & 120 & 69,4 \\
\hline 24 & Kalimantan Utara & 46 & 15 & 32,6 & 31 & 67,4 \\
\hline 25 & Sulawesi Utara & 185 & 48 & 25,9 & 137 & 74,1 \\
\hline 26 & Sulawesi Tengah & 189 & 80 & 42,3 & 109 & 57,7 \\
\hline 27 & Sulawesi Selatan & 448 & 204 & 45,5 & 244 & 54,5 \\
\hline 28 & Sulawesi Tenggara & 268 & 42 & 15,7 & 226 & 84,3 \\
\hline 29 & Gorontalo & 93 & 24 & 25,8 & 69 & 74,2 \\
\hline 30 & Sulawesi Barat & 94 & 28 & 29,8 & 66 & 70,2 \\
\hline 31 & Maluku & 198 & 24 & 12,1 & 174 & 87,9 \\
\hline 32 & Maluku Utara & 127 & 22 & 17,3 & 105 & 82,7 \\
\hline 33 & Papua Barat & 150 & 20 & 13,3 & 130 & 86,7 \\
\hline 34 & Papua & 372 & 20 & 5,4 & 352 & 94,6 \\
\hline & INDONESIA & 9.697 & 3.696 & 38,1 & 6.001 & 61,9 \\
\hline
\end{tabular}

Sumber data: Risnakes, 2017

Tabel 2 menunjukkan jumlah ratarata puskesmas di setiap provinsi di Indonesia yang sudah mendapat pelatihan PIS-PK sebanyak 38,1\%. Provinsi dengan persentase paling besar untuk Puskesmas yang sudah mendapat pelatihan PIS-PK yaitu Provinsi Lampung yang mencapai 72,2\% Puskesmas, sedangkan sebanyak
94,6\% Puskesmas di Provinsi Papua belum mendapat pelatihan PIS-PK.

Kesiapan manajemen untuk Puskesmas yang sudah mendapat pelatihan PIS-PK dapat dilihat pada Tabel 3 sedangkan kesiapan manajemen untuk Puskesmas yang belum mendapat pelatihan PIS-PK dapat dilihat pada Tabel 4. 
Tabel 3. Persentase kesiapan manajemen puskesmas yang sudah dilatih PIS-PK dalam menjalankan PIS-PK

\begin{tabular}{|c|c|c|c|c|c|c|c|c|c|c|}
\hline \multirow{2}{*}{ No. } & \multirow{2}{*}{ Nama Provinsi } & \multirow{2}{*}{$\begin{array}{c}\text { Jumlah } \\
\text { Puskesmas } \\
\text { dilatih PIS } \\
\text { PK }\end{array}$} & \multicolumn{2}{|c|}{ Kesiapan P1 } & \multicolumn{2}{|c|}{ Kesiapan P2 } & \multicolumn{2}{|c|}{ Kesiapan P3 } & \multicolumn{2}{|c|}{$\begin{array}{c}\text { Kesiapan } \\
\text { Manajemen }\end{array}$} \\
\hline & & & Siap & $\begin{array}{c}\text { Kurang } \\
\text { Siap }\end{array}$ & Siap & $\begin{array}{c}\text { Kurang } \\
\text { Siap }\end{array}$ & Siap & $\begin{array}{l}\text { Kurang } \\
\text { Siap }\end{array}$ & Siap & $\begin{array}{c}\text { Kurang } \\
\text { Siap }\end{array}$ \\
\hline 1 & Aceh & 195 & 58.5 & 41.5 & 65.1 & 34.9 & 81 & 18.9 & 69.7 & 30.2 \\
\hline 2 & Sumatra Utara & 292 & 62.7 & 37.3 & 63.4 & 36.6 & 65.8 & 34.3 & 65.8 & 34.2 \\
\hline 3 & Sumatra Barat & 109 & 79.8 & 20.2 & 78.9 & 21.1 & 85.3 & 14.7 & 86.2 & 13.8 \\
\hline 4 & Riau & 88 & 63.6 & 36.4 & 55.7 & 44.3 & 86.4 & 13.6 & 70.5 & 29.6 \\
\hline 5 & Jambi & 79 & 58.2 & 41.8 & 72.2 & 27.8 & 82.3 & 17.7 & 72.2 & 27.9 \\
\hline 6 & Sumatra Selatan & 128 & 77.3 & 22.7 & 75.8 & 24.2 & 84.4 & 15.6 & 85.2 & 14.8 \\
\hline 7 & Bengkulu & 51 & 74.5 & 25.5 & 68.6 & 31.4 & 74.5 & 25.5 & 84.3 & 15.7 \\
\hline 8 & Lampung & 210 & 78.1 & 21.9 & 87.1 & 12.9 & 79.0 & 21.0 & 85.7 & 14.3 \\
\hline 9 & Kep. Bangka Belitung & 26 & 84.6 & 15.4 & 65.4 & 34.6 & 73.1 & 26.9 & 73.1 & 26.9 \\
\hline 10 & Kepulauan Riau & 48 & 79.2 & 20.9 & 64.6 & 35.5 & 85.4 & 14.6 & 81.3 & 18.8 \\
\hline 11 & DKI Jakarta & 93 & 44.1 & 55.9 & 35.5 & 64.5 & 87.1 & 12.9 & 47.3 & 52.7 \\
\hline 12 & Jawa Barat & 352 & 67.3 & 32.6 & 75.0 & 25.0 & 87.5 & 12.5 & 76.7 & 23.3 \\
\hline 13 & Jawa Tengah & 474 & 84.2 & 15.8 & 84.6 & 15.4 & 89.9 & 10.1 & 92.2 & 7.8 \\
\hline 14 & DI Yogyakarta & 35 & 82.9 & 17.1 & 80.0 & 20.0 & 97.1 & 2.9 & 94.3 & 5.7 \\
\hline 15 & Jawa Timur & 481 & 81.3 & 18.7 & 81.7 & 18.3 & 89.6 & 10.4 & 87.3 & 12.7 \\
\hline 16 & Banten & 97 & 57.7 & 42.3 & 81.4 & 18.6 & 88.7 & 11.3 & 73.2 & 26.8 \\
\hline 17 & Bali & 50 & 72.0 & 28.0 & 80.0 & 20.0 & 98.0 & 2.0 & 86.0 & 14.0 \\
\hline 18 & Nusa Tenggara Barat & 95 & 70.5 & 29.5 & 64.2 & 35.8 & 85.3 & 14.7 & 72.6 & 27.4 \\
\hline 19 & Nusa Tenggara Timur & 42 & 61.9 & 38.1 & 76.2 & 23.8 & 76.2 & 23.8 & 73.8 & 26.2 \\
\hline 20 & Kalimantan Barat & 61 & 52.5 & 47.5 & 60.7 & 39.3 & 83.6 & 16.4 & 63.9 & 36.0 \\
\hline 21 & Kalimantan Tengah & 29 & 72.4 & 27.6 & 69.0 & 31.0 & 72.4 & 27.5 & 72.4 & 27.5 \\
\hline 22 & Kalimantan Selatan & 81 & 71.6 & 28.4 & 76.5 & 23.5 & 90.1 & 9.9 & 85.2 & 14.8 \\
\hline 23 & Kalimantan Timur & 53 & 54.7 & 45.3 & 54.7 & 45.3 & 79.2 & 20.8 & 60.4 & 39.6 \\
\hline 24 & Kalimantan Utara & 15 & 66.7 & 33.4 & 46.7 & 53.3 & 93.3 & 6.7 & 80.0 & 20.0 \\
\hline 25 & Sulawesi Utara & 48 & 70.8 & 29.2 & 77.1 & 22.9 & 91.7 & 8.3 & 85.4 & 14.6 \\
\hline 26 & Sulawesi Tengah & 80 & 61.3 & 38.8 & 57.5 & 42.5 & 70.0 & 30.0 & 66.3 & 33.8 \\
\hline 27 & Sulawesi Selatan & 204 & 77.9 & 22.1 & 82.4 & 17.6 & 82.4 & 17.7 & 85.8 & 14.2 \\
\hline 28 & Sulawesi Tenggara & 42 & 69.0 & 31.0 & 83.3 & 16.7 & 78.6 & 21.4 & 88.1 & 11.9 \\
\hline 29 & Gorontalo & 24 & 58.3 & 41.7 & 79.2 & 20.9 & 87.5 & 12.5 & 66.7 & 33.4 \\
\hline 30 & Sulawesi Barat & 28 & 64.3 & 35.7 & 82.1 & 17.9 & 82.1 & 17.9 & 78.6 & 21.4 \\
\hline 31 & Maluku & 24 & 54.2 & 45.9 & 58.3 & 41.6 & 58.3 & 41.7 & 58.3 & 41.6 \\
\hline 32 & Maluku Utara & 22 & 63.6 & 36.3 & 59.1 & 40.9 & 68.2 & 31.8 & 59.1 & 40.9 \\
\hline 33 & Papua Barat & 20 & 60.0 & 40.0 & 85.0 & 15.0 & 50.0 & 50.0 & 70.0 & 30.0 \\
\hline 34 & Papua & 20 & 25.0 & 75.0 & 50.0 & 50.0 & 70.0 & 30.0 & 35.0 & 65.0 \\
\hline & INDONESIA & 3.696 & 71 & 28.9 & 74 & 26 & 83.4 & 16.6 & 78.8 & 21.2 \\
\hline
\end{tabular}

Sumber data: Risnakes, 2017 
Tabel 4. Persentase kesiapan manajemen puskesmas yang belum dilatih PIS-PK dalam menjalankan PIS-PK

\begin{tabular}{|c|c|c|c|c|c|c|c|c|c|c|}
\hline \multirow[b]{2}{*}{ No. } & \multirow[b]{2}{*}{ Nama Provinsi } & \multirow{2}{*}{$\begin{array}{c}\text { Jumlah } \\
\text { Puskesmas } \\
\text { belum } \\
\text { dilatih PIS } \\
\text { PK }\end{array}$} & \multicolumn{2}{|c|}{ Kesiapan P1 } & \multicolumn{2}{|c|}{ Kesiapan P2 } & \multicolumn{2}{|c|}{ Kesiapan P3 } & \multicolumn{2}{|c|}{$\begin{array}{c}\text { Kesiapan } \\
\text { Manajemen }\end{array}$} \\
\hline & & & Siap & $\begin{array}{l}\text { Kurang } \\
\text { Siap }\end{array}$ & Siap & $\begin{array}{l}\text { Kurang } \\
\text { Siap }\end{array}$ & Siap & $\begin{array}{l}\text { Kurang } \\
\text { Siap }\end{array}$ & Siap & $\begin{array}{c}\text { Kurang } \\
\text { Siap }\end{array}$ \\
\hline 1 & Aceh & 145 & 50.3 & 49.7 & 60.0 & 40.0 & 71.7 & 28.3 & 37.9 & 62.0 \\
\hline 2 & Sumatra Utara & 279 & 56.6 & 43.4 & 26.5 & 73.5 & 55.2 & 44.8 & 35.1 & 64.9 \\
\hline 3 & Sumatra Barat & 155 & 65.2 & 34.9 & 67.1 & 32.9 & 78.1 & 21.9 & 63.2 & 36.8 \\
\hline 4 & Riau & 124 & 58.1 & 42.0 & 54.0 & 45.9 & 72.6 & 27.4 & 51.6 & 48.4 \\
\hline 5 & Jambi & 97 & 77.3 & 22.6 & 72.2 & 27.8 & 86.6 & 13.4 & 73.2 & 26.8 \\
\hline 6 & Sumatra Selatan & 194 & 64.9 & 35.1 & 40.7 & 59.3 & 73.7 & 26.3 & 54.1 & 45.9 \\
\hline 7 & Bengkulu & 128 & 73.4 & 26.5 & 50.0 & 50.0 & 74.2 & 25.8 & 53.9 & 46.1 \\
\hline 8 & Lampung & 81 & 49.4 & 50.6 & 34.6 & 65.4 & 59.3 & 40.8 & 38.3 & 61.7 \\
\hline 9 & Kep. Bangka Belitung & 36 & 72.2 & 27.7 & 61.1 & 38.9 & 80.6 & 19.5 & 66.7 & 33.3 \\
\hline 10 & Kepulauan Riau & 24 & 54.2 & 45.8 & 33.3 & 66.7 & 54.2 & 45.9 & 41.7 & 58.3 \\
\hline 11 & DKI Jakarta & 221 & 35.3 & 64.7 & 14.0 & 86.0 & 46.2 & 53.9 & 16.7 & 83.2 \\
\hline 12 & Jawa Barat & 698 & 62.2 & 37.8 & 62.6 & 37.4 & 77.5 & 22.5 & 60.3 & 39.6 \\
\hline 13 & Jawa Tengah & 401 & 66.6 & 33.4 & 70.6 & 29.4 & 76.6 & 23.5 & 65.1 & 35.0 \\
\hline 14 & DI Yogyakarta & 86 & 51.2 & 48.9 & 84.9 & 15.1 & 86.0 & 13.9 & 55.8 & 44.2 \\
\hline 15 & Jawa Timur & 479 & 63.9 & 36.1 & 61.8 & 38.2 & 68.5 & 31.6 & 63.0 & 36.9 \\
\hline 16 & Banten & 136 & 43.4 & 56.7 & 55.1 & 44.9 & 76.5 & 23.5 & 45.6 & 54.4 \\
\hline 17 & Bali & 70 & 82.9 & 17.2 & 84.3 & 15.7 & 85.7 & 14.3 & 77.1 & 22.8 \\
\hline 18 & Nusa Tenggara Barat & 63 & 54.0 & 46.0 & 42.9 & 57.2 & 60.3 & 39.7 & 39.7 & 60.3 \\
\hline 19 & Nusa Tenggara Timur & 329 & 72.0 & 28.0 & 53.8 & 46.2 & 76.6 & 23.4 & 65.7 & 34.3 \\
\hline 20 & Kalimantan Barat & 177 & 65.5 & 34.5 & 36.2 & 63.8 & 74.0 & 26.0 & 50.8 & 49.2 \\
\hline 21 & Kalimantan Tengah & 166 & 59.6 & 40.3 & 35.5 & 64.4 & 67.5 & 32.6 & 48.2 & 51.8 \\
\hline 22 & Kalimantan Selatan & 149 & 59.7 & 40.3 & 47.7 & 52.3 & 72.5 & 27.5 & 49.7 & 50.4 \\
\hline 23 & Kalimantan Timur & 120 & 57.5 & 42.5 & 35.8 & 64.2 & 64.2 & 35.9 & 38.3 & 61.7 \\
\hline 24 & Kalimantan Utara & 31 & 54.8 & 45.2 & 51.6 & 48.4 & 45.2 & 54.9 & 35.5 & 64.5 \\
\hline 25 & Sulawesi Utara & 137 & 59.1 & 40.8 & 51.1 & 48.9 & 85.4 & 14.6 & 56.9 & 43.1 \\
\hline 26 & Sulawesi Tengah & 109 & 69.7 & 30.3 & 35.8 & 64.2 & 67.9 & 32.1 & 47.7 & 52.2 \\
\hline 27 & Sulawesi Selatan & 244 & 66.8 & 33.2 & 51.6 & 48.4 & 79.1 & 20.9 & 65.2 & 34.9 \\
\hline 28 & Sulawesi Tenggara & 226 & 64.2 & 35.8 & 36.7 & 63.2 & 75.2 & 24.8 & 46.0 & 54.0 \\
\hline 29 & Gorontalo & 69 & 62.3 & 37.7 & 69.6 & 30.4 & 73.9 & 26.0 & 49.3 & 50.7 \\
\hline 30 & Sulawesi Barat & 66 & 71.2 & 28.7 & 39.4 & 60.7 & 74.2 & 25.8 & 59.1 & 40.9 \\
\hline 31 & Maluku & 174 & 73.0 & 27.0 & 23.6 & 76.5 & 62.6 & 37.3 & 43.1 & 56.9 \\
\hline 32 & Maluku Utara & 105 & 58.1 & 41.9 & 35.2 & 64.8 & 81.9 & 18.1 & 43.8 & 56.2 \\
\hline 33 & Papua Barat & 130 & 37.7 & 62.4 & 14.6 & 85.4 & 39.2 & 60.8 & 10.8 & 89.2 \\
\hline 34 & Papua & 352 & 29.5 & 70.5 & 9.1 & 90.9 & 34.7 & 65.3 & 11.6 & 88.4 \\
\hline & INDONESIA & 6.001 & 59.7 & 40.3 & 47.2 & 52.8 & 69.2 & 30.8 & 49.9 & 50.1 \\
\hline
\end{tabular}

Sumber data: Risnakes, 2017

Tabel 3 dan 4 menunjukkan bahwa secara nasional, manajemen Puskesmas dalam menjalankan PIS-PK lebih siap pada Puskesmas yang sudah mendapat pelatihan PIS-PK. Pada Puskesmas yang sudah mendapat pelatihan PIS-PK, kesiapan manajemen meningkat di setiap tahapannya, yaitu dari tahapan P1 (Perencanaan) ke P2 (Penggerakan-Pelaksanaan), dan dari tahapan P2 (Penggerakan-Pelaksanaan) ke P3 (Pengawasan-Pengendalian-Penilaian).

Sedangkan pada Puskesmas yang belum mendapat pelatihan PIS-PK, kesiapan pada tahap P1 (Perencanaan) lebih besar dibanding kesiapan pada tahap P2 (PenggerakanPelaksanaan), namun kesiapan pada tahap P2 (Penggerakan-Pelaksanaan) lebih kecil dibanding kesiapan pada tahap P3 (Pengawasan-Pengendalian-Penilaian).

Berdasarkan provinsi, untuk puskesmas yang sudah mendapat pelatihan PIS-PK dan dinilai paling siap secara manajemen dalam menjalankan PIS-PK terdapat di Provinsi Daerah Istimewa Yogyakarta $(94,3 \%)$, kemudian Jawa Tengah $(92,2 \%)$ dan Sulawesi Tenggara $(88,1 \%)$. 
Sedangkan untuk puskesmas yang belum mendapat pelatihan PIS-PK namun dinilai siap secara manajemen untuk menjalankan PIS-PK yaitu Puskesmas di Provinsi Bali $(77,1 \%)$, kemudian Jambi $(73,2 \%)$ dan Kepulauan Bangka Belitung (66,7\%).

\section{PEMBAHASAN}

Permenkes Nomor 43 Tahun 2019 pasal 4 ayat (1) menyebutkan bahwa "Puskesmas mempunyai tugas melaksanakan kebijakan kesehatan untuk mencapai tujuan pembangunan kesehatan di wilayah kerjanya", sedangkan pada ayat (2) dituliskan "Untuk mencapai tujuan pembangunan kesehatan sebagaimana dimaksud pada ayat (1), Puskesmas mengintegrasikan program yang dilaksanakannya dengan pendekatan keluarga." Kemudian pada ayat (3) dituliskan bahwa "Pendekatan keluarga sebagaimana dimaksud pada ayat (2) merupakan salah satu cara Puskesmas mengintegrasikan program untuk meningkatkan jangkauan sasaran dan mendekatkan akses pelayanan kesehatan di wilayah kerjanya dengan mendatangi keluarga."

PIS-PK terdiri atas 4 (empat) area prioritas yang meliputi: penurunan angka kematian ibu dan bayi, penurunan prevalensi balita pendek (stunting), penanggulangan penyakit menular, dan penanggulangan penyakit tidak menular. PIS-PK menetapkan 12 (dua belas) indikator utama sebagai penanda status kesehatan sebuah keluarga, yaitu: keluarga mengikuti program Keluarga Berencana (KB), ibu melakukan persalinan di fasilitas kesehatan, bayi mendapat imunisasi dasar lengkap, bayi mendapat Air Susu Ibu (ASI) eksklusif, balita mendapatkan pemantauan pertumbuhan, penderita tuberkulosis paru mendapatkan pengobatan sesuai standar, penderita hipertensi melakukan pengobatan secara teratur, penderita gangguan jiwa mendapatkan pengobatan dan tidak ditelantarkan, anggota keluarga tidak ada yang merokok, keluarga sudah menjadi anggota Jaminan Kesehatan Nasional (JKN), keluarga mempunyai akses sarana air bersih, dan keluarga mempunyai akses atau menggunakan jamban sehat (Kementerian Kesehatan, 2016a). Keberhasilan pelaksanaan program kesehatan dipengaruhi oleh pendekatan, kebijakan, dan strategi program yang tepat serta sasaran yang jelas agar sumber daya yang ada dapat dimanfaatkan secara efektif dan efisien, maka program kesehatan diselenggarakan secara terintegrasi mulai dari perencanaan sampai ke pelaksanaan, pemantauan dan evaluasinya (Kementerian Kesehatan, 2017a).

Dalam melaksanakan tugas dan fungsi terkait PIS-PK diperlukan suatu manajemen, dengan serangkaian proses yang meliputi perencanaan, pengorganisasian, pelaksanaan dan kontrol (Planning, Organizing, Actuating, Controling) untuk mencapai sasaran/tujuan secara efektif dan efesien. Makna efektif yaitu tujuan dapat dicapai melalui proses penyelenggaraan yang baik, benar dan bermutu, berdasarkan hasil analisis situasi yang evidence based. Sedangkan makna efisien yaitu puskesmas mampu memanfaatkan sumber daya yang ada untuk menyelenggarakan upaya kesehatan sesuai standar dengan baik dan benar, sehingga kinerja dapat terwujud sesuai target (Kementerian Kesehatan, 2016b).

Hasil penelitian ini menunjukkan bahwa manajemen puskesmas yang sudah mendapat pelatihan PIS-PK lebih siap dibanding puskesmas yang belum mendapat pelatihan PIS-PK. Pelatihan sangat penting peranannya dalam meningkatkan kompetensi tenaga kesehatan pelaksana PIS-PK. Hasil studi yang dilakukan oleh Puslitbang Sumber Daya dan Pelayanan Kesehatan pada tahun 2017, menunjukkan bahwa kepala puskesmas yang mengikuti pelatihan Keluarga Sehat lebih memahami dan mampu merencanakan tindak lanjut pelaksanaan PIS-PK di wilayah kerjanya pasca pelatihan dengan baik (Laelasari, Anwardan Soerachman, 2017).

Menurut Petunjuk Teknis Penguatan Manajemen Puskesmas dengan Pendekatan Keluarga, Perencanaan (P1) adalah tahap menyusun Rencana Usulan Kegiatan (RUK) dan Rencana Pelaksanaan Kegiatan (RPK) yang didasari oleh fakta dan data. Penggerakan-Pelaksanaan (P2) adalah tahap melaksanakan hal-hal yang sudah tercantum dalam RPK dan mendorong pencapaiannya melalui lokakarya mini (lokmin) secara berkala. Pengawasan-Pengendalian-Penilaian (P3) adalah tahap memantau perkembangan pencapaian (yang juga dilakukan melalui 
lokmin berkala), melakukan koreksi pelaksanaan kegiatan, dan menilai pencapaian kegiatan pada pertengahan dan akhir tahun (Kementerian Kesehatan, 2016c). Penentuan Puskesmas sebagai lokasi fokus (lokus) PIS-PK tidak ditentukan seluruhnya untuk kurun waktu satu tahun, namun sudah dilakukan bertahap mulai dari Tahun 2016 dan diharapkan seluruh Puskesmas sudah menjalankan PIS-PK di Tahun 2019. Namanama Puskesmas sebagai lokus PIS-PK per tahunnya ditentukan melalui Keputusan Menteri Kesehatan, sebagai contoh untuk Tahun 2018, dikeluarkan Keputusan Menteri Kesehatan Nomor HK.01.07/Menkes/42/2018 tentang Lokus Program Indonesia Sehat dengan Pendekatan Keluarga Tahun 2018 yang menetapkan 3.279 Puskesmas di 514 kabupaten/kota pada 34 provinsi sebagai lokus Program Indonesia Sehat dengan Pendekatan Keluarga Tahun 2018 (Kementerian Kesehatan, 2018). Puskesmas yang sudah ditetapkan sebagai lokus PIS-PK ini yang kemudian akan diundang untuk mengikuti pelatihan PIS-PK atau disebut juga Pelatihan Keluarga Sehat yang diselenggarakan oleh Bapelkes atau Dinas Kesehatan Provinsi. Dalam pelatihan PIS-PK ini, sudah ada penetapan kurikulum standar yang akan diberikan ke peserta pelatihan oleh pengajar atau narasumber yang sudah dinilai kompeten. Materi yang diberikan meliputi materi dasar tentang kebijakan PIS-PK dan materi inti yang meliputi 12 indikator PIS-PK, komunikasi efektif, dan manajemen pendekatan keluarga (Kementerian Kesehatan RI, 2017). Oleh karena itu, menjadi hal yang wajar jika puskesmas yang sudah dilatih PIS-PK menjadi lebih siap secara manajerial dibandingkan dengan puskesmas yang belum dilatih PIS-PK karena tenaga kesehatan yang dikirimkan oleh puskesmas untuk mengikuti pelatihan ini mendapatkan penguatan kompetensi khusus tentang PIS-PK.

Selain dari faktor keikutsertaan dalam pelatihan PIS-PK, manajemen puskesmas yang sudah dilatih PIS-PK lebih siap dibanding puskesmas yang belum dilatih PIS-PK. Hal ini dikarenakan variabelvariabel yang dinilai untuk setiap tahap manajemen pada puskesmas yang sudah dilatih PIS-PK nilainya lebih tinggi dibanding pada puskesmas yang belum dilatih PIS-PK.

Berdasarkan provinsi, hasil penelitian ini menunjukkan bahwa untuk puskesmas yang sudah mendapat pelatihan PIS-PK, Provinsi Daerah Istimewa Yogyakarta $(94,3 \%)$, Jawa Tengah $(92,2 \%)$ dan Sulawesi Tenggara $(88,1 \%)$ adalah tiga provinsi yang paling siap secara manajemen dalam menjalankan PIS-PK. Puskesmas yang sudah dilatih PIS-PK di Provinsi Daerah Istimewa Yogyakarta (DIY) memiliki nilai kesiapan manajemen yang paling tinggi dibandingkan provinsi lain. Hal ini disebabkan karena 97,7\% puskesmas di Provinsi DIY sudah memiliki tim Keluarga Sehat, $100 \%$ puskesmas sudah melakukan sosialisasi PIS-PK, 80\% puskesmas memiliki RUK dan RPK dengan PIS-PK di dalamnya, $82,9 \%$ puskesmas sudah memiliki anggaran untuk PIS-PK, 97,1\% puskesmas sudah memiliki instrumen PIS-PK, $100 \%$ puskesmas memiliki pengumpul data PISPK, $100 \%$ puskesmas sudah memiliki komputer dengan akses internet, 94,3\% puskesmas sudah melaksanakan lokakarya mini bulanan, 94,8\% puskesmas sudah melaksanakan lokakarya mini triwulanan, $100 \%$ puskesmas melakukan evaluasi kehadiran petugas puskesmas, dan 98,6\% puskesmas sudah melakukan evaluasi kinerja. Hal ini menunjukkan bahwa di Provinsi DIY, baik perencanaan, penggerakan dan penilaian/evaluasi pelaksanaan PIS-PK sudah berjalan baik. Terkait dengan fungsi P1, P2 dan P3, hasil studi yang dilakukan oleh Henni, dkk (2018) di Kota Bengkulu menyimpulkan bahwa fungsi perencanaan, pelaksanaan, pengendalian dan evaluasi berperan dalam pencapaian indikator komitmen pelayanan. Hasil studi tersebut juga menunjukkan bahwa semakin baik fungsi manajemen maka semakin tinggi pula indikator komitmen layanan (Febriawati et al., 2018). Indikator komitmen pelayanan meliputi beberapa aspek. Pertama adalah Angka Kontak yang merupakan indikator untuk mengetahui tingkat aksesabilitas dan pemanfaatan pelayanan primer di FKTP oleh peserta berdasarkan jumlah peserta JKN (per nomor identitas peserta). Indikator kedua adalah Rasio Rujukan Rawat Jalan Non Spesialistik untuk mengetahui kualitas pelayanan di 
FKTP, sehingga sistem rujukan terselenggara sesuai indikasi medis dan kompetensi FKTP. Selanjutnya yang menjadi indikator ketiga adalah Rasio Peserta Prolanis (Program Pengelolaan Penyakit Kronis) Rutin Berkunjung ke FKTP, yang merupakan indikator untuk mengetahui kesinambungan pelayanan penyakit kronis yang disepakati oleh BPJS Kesehatan dan FKTP terhadap peserta Prolanis.

Ketersediaan SDM dalam melaksanakan PIS-PK di puskesmas di DIY sudah tersedia, ditunjukkan dengan 97,7\% puskesmas di Provinsi DIY sudah memiliki tim Keluarga Sehat dan 100\% puskesmas sudah memiliki petugas untuk mengumpulkan data PIS-PK. SDM merupakan salah satu subsistem di dalam Sistem Kesehatan Nasional yang memiliki peran penting. Dalam Joint Learning Initiative (2004) disebutkan bahwa peran SDM dalam sistem kesehatan adalah sebagai perekat yang mengatur dan menyinkronkan seluruh sumber daya yang ada di dalam sistem kesehatan seperti anggaran kesehatan, teknologi, obat-obatan, infrastruktur, dan juga informasi kesehatan. (The President and Fellows of Harvard College, 2004). Hasil penelitian yang dilakukan oleh Fatimah, D.N. (2018) di Puskesmas Anjir Pasar, Kabupaten Barito Kuala, menunjukkan bahwa pelaksanaan PIS-PK pada tahap persiapan, kunjungan rumah dan intervensi awal, input data dan analisis Indeks Keluarga Sehat (IKS) awal kurang maksimal, disebabkan salah satunya karena keterbatasan SDM (Fatimah, 2018).

Puskesmas di Provinsi DIY juga sudah banyak yang menyediakan anggaran untuk pelaksanaan PIS-PK. SDM dan anggaran merupakan dua aspek yang cukup penting yang harus disiapkan dalam tahap perencanaan puskesmas. Dalam Permenkes Nomor 39 tahun 2016 disebutkan bahwa Dinas Kesehatan Kabupaten/Kota berkewajiban untuk menjamin terpenuhinya Permenkes Nomor 75 Tahun 2014 (yang saat ini menjadi Permenkes Nomor 43 tahun 2019), termasuk pemenuhan SDM dan anggaran untuk pelaksanaan PIS-PK (Kementerian Kesehatan, 2016a). Pemenuhan SDM dapat dilakukan dengan merekrut tenaga tambahan dengan syarat yang telah ditetapkan oleh Dinas Kesehatan Kabupaten/Kota, memberdayakan tenaga Nusantara Sehat yang ditempatkan di puskesmas tersebut, atau bekerjasama dengan universitas atau institusi pendidikan untuk membantu dalam kegiatan kunjungan rumah hingga entry data PIS-PK. Penelitian mengenai bagaimana implementasi PIS-PK menggunakan tenaga kontrak di Kabupaten Kulon Progo menunjukkan bahwa terdapat faktor pendukung dan penghambat yang mempengaruhi strategi pelaksanaan PIS-PK menggunakan tenaga kontrak.(Shinta Chyntia Agustina, Trisnantoro and Handono, 2019) Faktor pendukung dengan adanya tenaga kontrak yaitu bisa mengurangi beban kerja petugas puskesmas, dan faktor penghambatnya antara lain belum adanya dukungan dalam akses informasi dan pelatihan untuk tenaga kontrak(Shinta Chyntia Agustina, Trisnantoro and Handono, 2019). Sedangkan untuk pemenuhan dari segi anggaran, Dinas Kesehatan Kabupaten/Kota maupun puskesmas dapat mengacu pada Permenkes Nomor 19 Tahun 2017 tentang Pedoman Pendanaan PIS-PK (Kementerian Kesehatan, 2017b).

Terkait dengan SDM dan anggaran, salah satu hal yang melatarbelakangi studi yang dilakukan oleh Astuti, T. S. R. and Soewondo, P. (2019) di Depok adalah adanya keterbatasan dari segi anggaran, SDM, kesulitan input data dan manajemen teknis pendataan. Anggaran dan SDM dalam sistem manajemen Puskesmas termasuk dalam item perencanaan. Studi tersebut menyarankan agar puskesmas dapat mengoptimalkam proses perencanaan serta pengalokasian SDM sesuai kebutuhan (Astuti and Soewondo, 2019). Pendanaan yang cukup juga dapat menjadi solusi bagi implementasi PIS-PK yang belum berhasil. Sebagai contoh, studi yang dilakukan di Kota Depok tentang analisa persiapan implementasi PIS-PK (indikator 8: kesehatan jiwa) menunjukkan bahwa implementasi PIS-PK (indicator 8: kesehatan jiwa) belum siap. Studi tersebut merekomendasikan perbaikan-perbaikan dari segi sumber daya, disposisi, dan struktur birokrasi. Selain itu, ketersediaan pendanaan yang cukup juga bisa menjadi solusi bagi hambatan yang ada (Roeslie, 2018). 
Selain SDM dan anggaran, hasil penelitian ini juga menunjukkan bahwa sarana-prasarana seperti komputer dengan akses internet sudah tersedia di seluruh puskesmas di Provinsi DIY. Seperti diketahui bahwa komputer dengan akses internet sangat penting dalam pelaksanaan PIS-PK untuk mengirimkan data-data keluarga yang sudah dikunjungi melalui aplikasi on line dan juga untuk keperluan analisis data menentukan IKS. Apabila komputer tidak dilengkapi dengan akses internet, tentunya akan menghambat pengiriman data-data tersebut. Sugiharti, dkk (2019) dalam tulisannya menuliskan bahwa belum semua puskesmas di Indonesia menggunakan aplikasi Keluarga Sehat karena sinyal internet yang kurang kuat (Sugiharti et al., 2019).

Hal lain yang penting adalah kemampuan SDM dalam memanfaatkan komputer tersebut untuk menjalankan aplikasi on line PIS-PK. Hasil penelitian Agni (2017) tentang Kesiapan DIY dalam penerapan PIS-PK diperoleh informasi bahwa kesiapan daerah dalam implementasi PIS-PK dirasa masih lemah, salah satunya adalah ketersediaan sarana prasarana penunjang termasuk keterbatasan kemampuan aplikasi on line. (Agni, 2018). Selain kemampuan SDM, pembagian tugas SDM dalam pelaksanaan PIS-PK ini juga menjadi hal yang penting. Hasil penelitian Virdasari, dkk (2018) juga menyebutkan bahwa implementasi PIS-PK di Puskesmas Mijen, Kota Semarang, belum sesuai dengan pedoman atau rencana yang disebabkan salah satunya oleh pembagian tugas SDM yang kurang tepat, sehingga berakibat pada target yang tidak tercapai (Virdasari, Arso and Fatmasari, 2018).

Aspek lain yang menyebabkan Provinsi DIY lebih siap secara manajemen dibanding provinsi lain adalah puskesmas sudah melaksanakan sosialisasi PIS-PK.

Penelitian yang dilakukan oleh Fitri Yanti dan Fithria (2018) menemukan bahwa 58,0\% petugas puskesmas di Puskesmas Kota Banda Aceh memiliki pengetahuan tinggi tentang PIS-PK (Yanti and Fithria, 2018). Petugas dengan pengetahuan yang baik tentang PIS-PK diharapkan dapat memberikan sosialisasi PIS-PK kepada masyarakat secara jelas dan lengkap, sehingga masyarakat juga akan memiliki pengetahuan tentang PIS-PK yang memadai sebagai bekal untuk mendukung pelaksanaan PIS-PK. Hal ini sesuai dengan hasil penelitian yang dilakukan oleh Budiwati, T.R.A (2019) yang menunjukkan ada hubungan yang signifikan antara pengetahuan, sikap dan tindakan (Budiwati, 2019).

Pada tahap penggerakan dan pelaksanaan, hampir seluruh puskesmas di Provinsi DIY sudah melaksanakan lokakarya mini bulanan dan triwulanan. Dalam Permenkes Nomor 44 tahun 2016 disebutkan bahwa penggerakan pelaksanaan program/kegiatan dapat dilakukan melalui berbagai cara, diantaranya adalah rapat dinas, pengarahan pada saat apel pegawai, pelaksanaan kegiatan dari setiap program sesuai penjadwalan pada Rencana Pelaksanaan Kegiatan (RPK) bulanan, maupun dilakukan melalui forum yang dibentuk khusus untuk itu. Forum yang dibentuk khusus untuk melakukan penggerakan pelaksanaan program/kegiatan dinamakan forum Lokakarya Mini Puskesmas. Lokakarya mini bulanan bertujuan untuk menilai sampai seberapa jauh pencapaian dan hambatan-hambatan yang dijumpai oleh para pelaksana program/kegiatan pada bulan atau periode yang lalu sekaligus pemantauan terhadap pelaksanaan rencana kegiatan Puskesmas yang akan datang; sehingga dapat dibuat perencanaan ulang yang lebih baik dan sesuai dengan tujuan yang hendak dicapai. Sedangkan lokakarya mini tribulanan bertujuan untuk menginformasikan dan mengidentifikasikan capaian hasil kegiatan tribulan sebelumnya, membahas dan memecahkan masalah dan hambatan yang dihadapi oleh lintas sektor pada kegiatan tribulan sebelumnya, dan menganalisa serta memutuskan Rencana Tindak Lanjut (RTL) dengan memasukkan aspek umpan balik dari masyarakat dan sasaran program.

Dari hasil evaluasi PIS-PK tahun 2016 oleh Laelasari, E., dkk diperoleh hasil bahwa komitmen dinas kabupaten dan Puskesmas dalam menjalankan PIS-PK sangat diperlukan. Komitmen tersebut diwujudkan melalui perencanaan SDM, 
alokasi anggaran, mekanisme pengumpulan data, serta sarana prasarana yang menunjang kegiatan PIS-PK. Selain itu keterlibatan lintas sektor juga diperlukan dalam upaya mempermudah gerak Puskesmas dalam mengimplementasikan tahapan kegiatan PISPK (Laelasari, Anwar and Soerachman, 2017). Hasil tersebut juga sesuai dengan yang ditunjukkan dari hasil studi di Kota Bengkulu bahwa peningkatan fungsi manajemen yang terintegrasi dan interkoneksi dapat dilakukan melalui perencanaan berdasarkan analisis situasi/kebutuhan, mengoptimalkan peran pemangku kepentingan lintas sektor, komitmen yang kuat, profesionalisme, dan pengawasan terpadu yang dievaluasi setiap bulan melalui lokakarya mini (Febriawati et al., 2018).

Pada tahap penilaian, pengendalian dan pengawasan, hampir seluruh puskesmas di Provinsi DIY sudah melakukan evaluasi kehadiran petugas puskesmas. Evaluasi ini penting untuk memgetahui kesanggupan petugas puskesmas untuk mentaati kewajiban datang, melaksanakan tugas, dan pulang sesuai ketentuan jam kerja. Evaluasi ini juga penting untuk mengetahui permasalahan yang terjadi, mengidentifikasi kekuatan, kelemahan, peluang dan ancaman sebagai bahan pertimbangan dalam menentukan kebijakan selanjutnya.

Hasil penelitian ini juga menunjukkan bahwa terdapat beberapa provinsi yang persentase kesiapan manajemennya lebih tinggi di atas persentase nasional $(49,9 \%)$ meskipun Puskesmas tersebut belum dilatih PIS-PK. Hal ini disebabkan karena nilai variabel di tahap P1, P2 dan P3 lebih besar dibandingkan dengan puskesmas lain. Kesiapan di tahap P1 dinilai dari ketersediaan Rencana Kerja Tahunan, ketersediaan sumber anggaran untuk kegiatan puskesmas, dan pengumpulan data perencanaan oleh petugas puskesmas. Kesiapan tahap P2 dinilai dari pelaksanaan apel pagi oleh puskesmas dan adanya lokakarya mini bulanan dan triwulanan. Kesiapan tahap P3 dinilai dari adanya kunjungan petugas dinas kesehatan untuk melakukan supervisi atau bimbingan teknis program, adanya pertemuan monitoring dan evaluasi program di Dinas Kesehatan, serta adanya penilaian kinerja. Hal tersebut bisa pula disebabkan karena sistem manajemen yang ada di Puskesmas sudah berjalan dengan baik, sehingga meskipun ada program baru, tidak menambah beban manajerial secara berarti. Selain itu, manajemen PIS-PK ini memang harapannya akan memperkuat manajemen Puskesmas yang sudah ada, karena masing-masing program akan terintegrasi mulai dari tahap P1, P2, hingga P3.

Jika dilihat dari kesiapan P1, P2 dan P3, hasil penelitian ini menunjukkan bahwa untuk puskesmas yang sudah dilatih PIS-PK maupun yang belum dilatih PIS-PK, kesiapan pada tahap P3 memiliki persentase lebih besar dibanding tahap P1 dan P2. Hal ini disebabkan oleh adanya evaluasi kehadiran petugas puskesmas dan evaluasi kinerja petugas kesehatan (di puskesmas yang sudah dilatih PIS-PK) dan adanya kunjungan petugas dinas kesehatan untuk melakukan supervisi atau bimbingan teknis program, adanya pertemuan monitoring dan evaluasi program di Dinas Kesehatan, serta adanya penilaian kinerja (di puskesmas yang belum dilatih PIS-PK). Sehingga dapat dikatakan bahwa monitoring dan evaluasi serta bimbingan teknis program memegang nilai penting dalam membangun kesiapan manajemen puskesmas secara utuh.

\section{KESIMPULAN DAN SARAN}

\section{Kesimpulan}

Manajemen Puskesmas dalam pelaksanaan PIS-PK lebih siap pada Puskesmas yang sudah melaksanakan pelatihan PIS-PK dibanding dengan Puskesmas yang belum melaksanakan pelatihan melaksanakan pelatihan PIS-PK. Kesiapan manajemen tersebut dihasilkan dari ketersediaan SDM, anggaran, disusunnya RUK dan RPK, ketersediaan instrumen PISPK, pelaksanaan sosialisasi, ketersediaan komputer dengan akses internet, dilakukannya lokmin bulanan dan triwulanan, serta adanya evaluasi kehadiran.

\section{Saran}

Agar puskesmas siap secara manajemen dalam pelaksanaan PIS-PK, 
maka perlu disiapkan ketersediaan, kemampuan dan pembagian kerja SDM, ketersediaan anggaran, ketersediaan sarana dan prasarana untuk melaksanakan PIS-PK seperti komputer dengan akses internet, instrumen Keluarga Sehat dan aplikasi Keluarga Sehat, dilaksanakannya lokmin bulanan dan triwulanan yang membahas PISPK, dan Puskesmas diharapkan dapat melakukan monitoring dan evaluasi internal terhadap dirinya sendiri, misalnya dari evaluasi kehadiran petugas dan penilaian kinerja di tiap program. Selain itu, fungsi Dinas kesehatan kabupaten/kota juga diharapkan dapat didorong untuk melakukan monitoring dan evaluasi secara rutin, supervisi serta melakukan pertemuan untuk memberikan umpan balik dan membahas rencana tindak lanjut dari hasil monitoring dan evaluasi. Dinas kesehatan kabupaten juga diharapkan memberikan bimbingan teknis program kepada puskesmas terkait pelaksanaan PIS-PK.

\section{UCAPAN TERIMAKASIH}

Ucapan terimakasih Penulis kepada Badan Litbangkes yang telah melaksanakan Risnakes sehingga penulis dapat memanfaatkan datanya untuk penulisan artikel ini. Terima kasih juga penulis sampaikan kepada Harimat Hendarwan dan Hendrianto Trisnowibowo yang telah memberikan dukungan dan saran dalam penyusunan artikel ini.

\section{KONTRIBUTOR PENULIS}

Kontributor utama dalam artikel ini adalah Mujiati dan kontributor anggota yaitu Sugiharti, Siti Masitoh dan Eva Laelasari.

\section{DAFTAR PUSTAKA}

Agni, M. G. K. (2018) 'Kesiapan Daerah Istimewa Yogyakarta dalam Penerapan Program Indonesia Sehat dengan Pendekatan Keluarga', Jurnal Formil (Forum Ilmiah) Kesmas Respati, 13(1).

Astuti, T. S. R. and Soewondo, P. (2019) 'Analisis Kesiapan Pembiayaan Hipertensi, Diabetes Melitus dan Gangguan Jiwa dalam Mendukung Program Indonesia Sehat dengan Pendekatan Keluarga (PIS PK) Tahun 2018-
2020', Jurnal Ekonomi Kesehatan Indonesia, $3(1)$.

Budiwati, T. R. A. (2019) Pengaruh Sosialisasi Gerakan Masyarakat Hidup Sehat (GERMAS) Terhadap Perilaku Konsumsi Buah dan Sayur Pada Siswa SMP Kasih Depok Tahun 2019 (Doctoral dissertation). Jakarta: Universitas Pembangunan Nasional Veteran Jakarta)

Fatimah, D. (2018) Implementasi Program Indonesia Sehat dengan Pendekatan Keluarga (PIS-PK) di Puskesmas Anjir Pasar Kabupaten Barito Kuala (D)isertasi. Universitas Gadjah Mada.

Febriawati, H. et al. (2018) 'The role of management function to the achievement of puskesmas indicator as a gatekeeper of national health guarantee in Bengkulu City', Indian Journal of Public Health Research \& Development, 9(9), pp. 353-7.

Kementerian Kesehatan (2016a) Peraturan Menteri Kesehatan Nomor 39 Tahun 2016 tentang Pedoman Penyelenggaraan Program Indonesia Sehat dengan Pendekatan Keluarga. Indonesia.

Kementerian Kesehatan (2016b) Peraturan Menteri Kesehatan Republik Indonesia Nomor 44 Tahun 2016 Tentang Pedoman Manajemen Puskesmas. Indonesia.

Kementerian Kesehatan (2016c) Petunjuk Teknis Penguatan Manajemen Puskesmas dengan Pendekatan Keluarga. Jakarta.

Kementerian Kesehatan (2017a) Modul Ajar Keluarga Sehat, Puslat SDMK Badan PPSDMK Kemenkes RI.

Kementerian Kesehatan (2017b) Peraturan Menteri Kesehatan Republik Indonesia Nomor 19 Tahun 2017 Tentang Pedoman Pendanaan Program Indonesia Sehat dengan Pendekatan Keluarga. Indonesia.

Kementerian Kesehatan (2018) Keputusan Menteri Kesehatan No. HK.01.07/Menkes/42/2018 tentang Lokus Program Indonesia Sehat dengan Pendekatan Keluarga Tahun 2018. Indonesia.

Kementerian Kesehatan RI (2014) Peraturan Menteri Kesehatan Republik Indonesia Nomor 75 Tahun 2014 tentang Pusat Kesehatan Masyarakat, $2014 . \quad$ doi: 10.1017/CBO9781107415324.004

Kementerian Kesehatan RI (2016) Peraturan Menteri Kesehatan Nomor 39 Tahun 2016 tentang Pedoman Penyelenggaraan Program Indonesia Sehat dengan Pendekatan Keluarga. Indonesia.

Kementerian Kesehatan RI (2017) Modul Ajar Keluarga Sehat, Puslat SDMK Badan PPSDMK Kemenkes RI. Jakarta.

Laelasari, E., Anwar, A. and Soerachman, R. (2017) 'Evaluasi Kesiapan Pelaksanaan Program Indonesia Sehat Dengan Pendekatan Keluarga', Jurnal Ekologi Kesehatan, 16(2), pp. 57-72.

Pusat Data dan Informasi Kementerian Kesehatan (2018) Program Indonesia Sehat dengan Pendekatan Keluarga, Semester I, 2017. Available at http://www.pusdatin.kemkes.go.id/resources/ 
download/pusdatin/buletin/buletin-pispk.pdf (Accessed: 28 June 2018).

Pusdatin Kemenkes RI (2018) Aplikasi Keluarga Sehat per 10 Februari 2018

Republik Indonesia (2012) Peraturan Presiden Republik Indonesia Nomor 72 Tahun 2012 Tentang Sistem Kesehatan Nasional.

Roeslie, E. (2018) 'Analisis Persiapan Implementasi Program Indonesia Sehat dengan Pendekatan Keluarga (Indikator 8: Kesehatan Jiwa) di Kota Depok tahun 2018', Jurnal Kebijakan Kesehatan Indonesia, 7(2), pp. 64-73.

Shinta Chyntia Agustina, Trisnantoro, L. and Handono, D. (2019) 'Implementasi Program Indonesia Sehat dengan Pendekatan Keluarga (PIS PK) Menggunakan Tenaga Kontrak di Kabupaten Kulon Progo Tahun 2018.', Jurnal Kebijakan Kesehatan Indonesia, 8(3), pp. 104-112.

Sugiharti, S. et al. (2019) 'Gambaran Ketersediaan Sumber Daya Manusia dan Prasarana Puskesmas dalam Pelaksanaan Program Indonesia Sehat dengan Pendekatan Keluarga
(PIS-PK): Analisis Data Risnakes 2017.', Jurnal Penelitian dan Pengembangan Pelayanan Kesehatan, pp. 31-39.

The President and Fellows of Harvard College (2004) Book Review: Human resources for health: overcoming the crisis. Washington: Communications Development Incorporated in Washington, D.C. doi 10.1177/146642400512500612.

Virdasari, E., Arso, S. P. and Fatmasari, E. Y. (2018) 'Analisis Kegiatan Pendataan Keluarga Program Indonesia Sehat Dengan Pendekatan Keluarga Di Puskesmas Kota Semarang (Studi Kasus pada Puskesmas Mijen)', Jurnal Kesehatan Masyarakat (e-Journal), 6(5), p. 52.

Yanti, F. and Fithria, F. (2018) 'Pengetahuan Petugas Kesehatan Tentang Program Indonesia Sehat Dengan Pendekatan Keluarga.', Jurnal Ilmiah Mahasiswa Fakultas Keperawatan, 3(3). 